\title{
Review
}

\section{Catalysis and Nanotechnologies}

\section{Seham A. Shaban}

Catalysts Laboratory, Egyptian Petroleum Research Institute, Cairo, Egypt.

\begin{abstract}
ANOTECHNOLOGY can be understood as a technology of design, fabrication and applications of nanostructures and nanomaterials, as well as fundamental understanding of physical properties and phenomena of nanomaterials and nanostructures. Nanomaterials, compared to bulk materials, have the scales ranging from individual atoms or molecules to submicron dimensions at least in one dimension. Nanomaterials and nanotechnology have found the significant applications in physical, chemical and biological systems. The discovery of novel materials, processes, and phenomena at the nanoscale, as well as the development of new experimental and theoretical techniques for research provide plenty of new opportunities for the development of innovative nanostructured materials. Nanostructured materials can be made with unique nanostructures and properties. This field is expected to open new venues in science and technology.
\end{abstract}

Keywords: Nanotechnology, Catalysis, Preparation and Characterization.

A major goal in catalysis research is to design catalysts that can achieve perfect selectivity and desirable activity. Between activity and selectivity, it is commonly accepted that the latter is much more difficult to achieve and control. A reaction of perfect selectivity would generate no waste products, thereby reduce energy and process requirements for separation and purification ${ }^{(1,2)}$.

Catalysts are of great importance in the modern world. Recently, almost all major chemicals are produced by catalytic processes. Among these catalytic processes, heterogeneous catalysis plays a very active role, because of environmental concerns: in the near future, non-environmentally friendly liquid acid catalysts will be replaced by green solid acid catalysts. To ensure an efficient reaction in heterogeneous catalysis, the active phase (usually the metal) on the catalyst surface must be highly dispersed over a large specific surface area and the specific activity maximized. To achieve this objective, catalytically active species are usually deposited as very fine particles on the surface of a highly porous support material (such as alumina, silica, titania, and zeolites) with high thermo-stability, high surface area, and suitable mechanical strength ${ }^{(3,4)}$.

E-mail: sehamshaban@yahoo.com 
Catalysts are used in all sectors of the chemical industry ${ }^{(5)}$ such as: basic chemistry; synthesis of nitric acid, sulphuric acid, ammonia, methanol and aromatics; in petrochemistry, synthesis of intermediate chemicals and polymers; refining, essentially in reactions of fluid-catalytic cracking and hydrotreatments; technologies for the abatement of pollutants, for removal of $\mathrm{NO}, \mathrm{CO}$ and hydrocarbons in emissions of stationary and mobile combustors; production of fine chemicals, for synthesis of intermediates and active compounds.

The field of nanocatalysis (the use of nanoparticles to catalyze reactions) has undergone an explosive growth during the past decade, both in homogeneous and heterogeneous catalysis $^{(6)}$. It can be seen from literature survey that catalysis with nanoparticles is a growing field. Since nanoparticles have a large surface-tovolume ratio compared to bulk materials, they are attractive to use as catalysts. The main apparent difference between bulk material and nanomaterial lays on the size difference. With the decrease of the particle size, distinctly different properties of nanomaterial emerge compared to its bulk structure. This makes the nanomaterials a class of novel materials with tremendous new applications. The terminal, size effects, is used to describe the properties change accompanied with particle size, with reducing particle size, the performance of surface atoms becomes dominant, as can be seen from Fig. 1, the surface atoms became dominant only when the palladium particle size reduced to below $10 \mathrm{~nm}^{(7)}$. Moreover, the properties changing with the particle size are also observed.

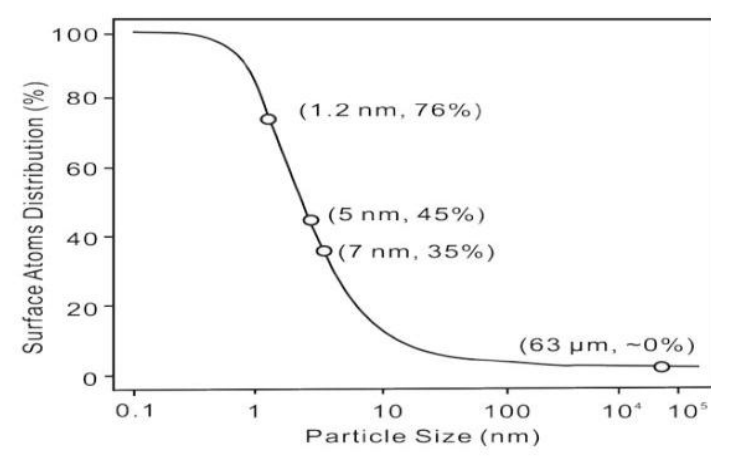

Fig. 1. The percentage of surface atoms changing with the palladium cluster diameter $^{(7)}$.

Heterogeneous catalysts enable many chemical transformations of fossil resources (natural gas, methane, liquid petroleum, coal..., etc.) into useful products $^{(8,9)}$. Catalysts are responsible for the production of over $60 \%$ of all chemicals and are used in some $90 \%$ of all chemical processes worldwide ${ }^{(10,11)}$. Catalyst manufacturing alone accounts for over $\$ 10$ billion in sales worldwide in four major sectors: refining, chemicals, polymerization, and exhaust emission catalysts. However, the value derived from catalyst sales is greatly eclipsed by

Egypt. J. Chem. 55, No. 5 (2012) 
the total value of the products that are produced. Products produced from fossil resources include chemical intermediates, polymers, plastic packaging, paints, cleaning products, pesticides, sweeteners, cosmetics, antibiotics, pharmaceuticals, and, of course, fuels. The global annual impact of «catalysis" is estimated to be $\$ 10$ trillion $^{(\mathbf{1 0})}$. As we look to the future, heterogeneous «catalysis increasingly holds the key to "green chemistry" and the promise of eliminating or at least dramatically curbing pollution from chemical and refining processes ${ }^{(12)}$, through atomically tailoring the structure of active and selective reaction sites in order to convert reactants directly to products without generating by-products that typically end up as harmful emissions ${ }^{(13)}$ or as wastes ${ }^{(14)}$.

The majority of industrial catalysts contain an active component in the form of nanoparticles $<20 \mathrm{~nm}$ in size that are dispersed onto high-surface-area supports. The importance of nanoparticles and nanostructure to the performance of catalysts has stimulated wide efforts to develop methods for their synthesis and characterization, making this area of study an integral part of nanoscience ${ }^{(15)}$.

\section{Classification of nanomaterials}

The nanomaterials formed are classified as zero-, one-, and two-dimension nanostructures;

1) Zero-dimention nanostructures, also named as nanoparticles, include single crystal, polycrystalline and amorphous particles with all possible morphologies, such as spheres, cubes and plates. Generally, the characteristic dimension of the particles is one hundred nanometres or bellow. Some other terminologies are zero-dimension nanostructures: If the nanoparticles are single crystalline, they are often referred to as nanocrystals. When the characteristic dimension of the nanoparticles is sufficiently small and quantum effects are observed, quantum dots are the common term used to describe such nanoparticles.

2) One-dimension (1D) nanostructures have various names including: whiskers, fibres, nanowires and nanorods. In many cases, nanotube and nanocables are also considered one-dimension structures. Although whiskers and nanorods are in general considered to have smaller length to thickness ratio (aspect ratio) than fibres and nanowires.

3) Thin films are two-dimensional nanostructures, another important nanostructure, and have been a subject of intensive study for almost a century, and many methods have been developed and improved.

\section{Synthesis approaches and techniques}

In order to explore novel physical properties and phenomena and realize potential applications of nanostructures and nanomaterials, the ability to fabricate and process nanomaterials and nanostructures is the first corner stone in nanotechnology. There are two approaches (Fig. 2) to syntheses nanomaterials and to fabricate the nanostructures: top-down and bottom-up. ${ }^{(4)}$ Top-down approach refers to slicing or successive cutting of a bulk material to get nanosized particles. Bottom-up approach refers to the build-up of a material from 
the bottom: atom-by-atom, molecule-by-molecule, or cluster-by-cluster. For example, milling is a typical top-down method in making nanoparticles, whereas the colloidal dispersion is a good example of bottom-up approach in the synthesis of nanoparticles (Fig. 2). Both approaches play very important roles in nanotechnology. Controlling growth of nanomaterials with different morphologies is of great importance because of the difference in resulted exposed crystalline surface. Specifically, in catalytic applications, this controlling is necessary for improving selectivity. Zaera et $a l^{(16)}$. reported the tuning of selectivity, by controlling Pt particle shape, in the formation of cis olefins to minimize the production of unhealthy trans fats during the partial hydrogenation of edible oils. The results shows clearly those tetrahedral $\mathrm{Pt}$ nanoparticles, which expose Pt (111) facets exclusively, exhibited better activity than sphere Pt particles with less (111) facets.

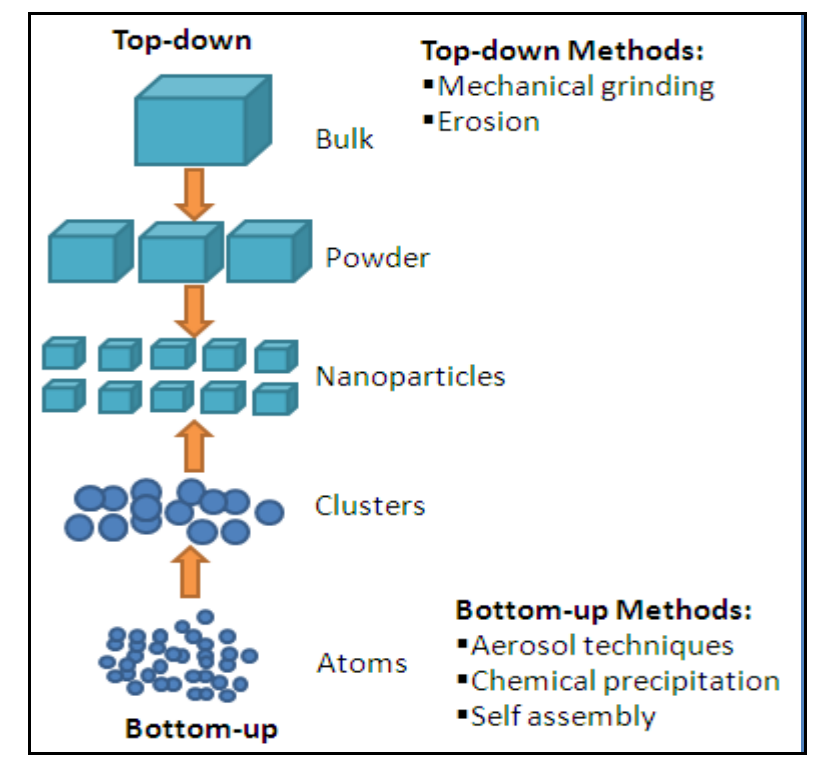

Fig. 2. Schematic representation of the 'bottom-up' and 'top-down' approaches of nanomaterials ${ }^{(9)}$.

\section{Characterization techniques}

Characterization of nanomaterials and nanostructures has been largely based on the surface analysis techniques and conventional characterization methods developed for bulk materials. For example, specific surface area (SSA) based on the measurement of the average particle size, pore volume and specific surface area of the catalyst samples prepared; X-ray diffraction (XRD) has been widely used for the determination of crystallinity. Crystal structures and lattice constants of nanoparticles, nanofibres and thin films; scanning electron microscopy (SEM) and transmission electron microscopy (TEM) together with electron diffraction 
used as routine techniques in characterization of nanoparticles; optical spectroscopy is frequently used to determine the size of semiconductor quantum dots or the band gap and electronic structures of semiconductors. Besides the established techniques of electron microscopy, diffraction methods and spectroscopic tools, scanning probe microscopy (SPM) is a relatively new characterization technique and has found wide spread applications in nanotechnology. The two major members of the SPM family are scanning tunneling microscopy (STM) and atomic force microscopy (AFM). Although both STM and AFM are true surface image techniques that can produce topographic images of a surface with atomic resolution in all three dimensions, combining with appropriately designed attachments, the STM and AFM have found a much broadened range of applications, such as nanoindentation, nanolithography, and patterned self-assembly. Almost all solid surfaces, whether hard or soft, electrically conductive or isolative, can all be studied with STM and AFM. Surfaces can be studied in gas (e.g. in air), in vacuum or in liquid.

\section{Methods of catalysts preparation}

Classification of the catalysts can be done using different criteria: (a) type of reaction in which they are used (b) chemical nature of the catalytic material (c) number of component (d) preparation procedure. The details of the manufacturing process for catalysts is a business secret of the catalyst manufacture. However, the most common (traditional) methods followed up for nanocatalyst preparation $^{(17)}$ are: precipitation or coprecipitation method, impregnation method, deposition method, sol-gel method and pyrolysis.

In addition, there are other methods used for preparation of nanoparticles, some of these methods are ${ }^{(18)}$ : High energy ball milling, photocatalysts, solvent extraction reduction, spray conversion reduction, transition metal salt reduction and microemulsion techniques.

\section{Preparation of catalysts by precipitation or coprecipitation method}

In this method, the precursors of active components, often in their salt forms (nitrate) is the preferred salt than chloride or sulfate; carboxylate is the best except it is more expensive and often less soluble in water; carbonate can not be used in preparing (basic catalysts), are first dissolved in water or suitable medium to form a homogeneous solution. The solution is then subjected to $\mathrm{pH}$ adjustment, it has been shown that by adjusting the $\mathrm{pH}$ and the ionic strength of the precipitation medium ${ }^{(19)}$, the size decreases as the $\mathrm{pH}$ and the ionic strength in the medium increases. During this precipitation, to which a precipitating agent is added, such as $\mathrm{NaOH}$ or $\mathrm{NaHCO}_{3}$, as a result hydroxides or hydroxy salts precipitate and form a homogenous mixture that is filtered off. This step is called hydrothermal process; the concentration of salt, temperature, the actual $\mathrm{pH}$ value, and the rate of $\mathrm{pH}$ change all influence crystal growth and their aggregation. Removal of $\mathrm{CO}_{2}$ and water during drying and calcination, and of oxygen during reduction, yields a porous catalyst. Calcination is undertaken to convert the salt or hydroxide form of the active components into oxides by reacting with air at 
suitable temperature, for instance, acetate, carbonate or nitrate decomposes into oxide. The catalysts also solidify into final form, i.e., amorphous into crystal; therefore, the surface and mechanical properties of the catalyst are decided mainly in this process. The flow sheet of the preparation of precipitated catalysts can be presented in Fig. 3.
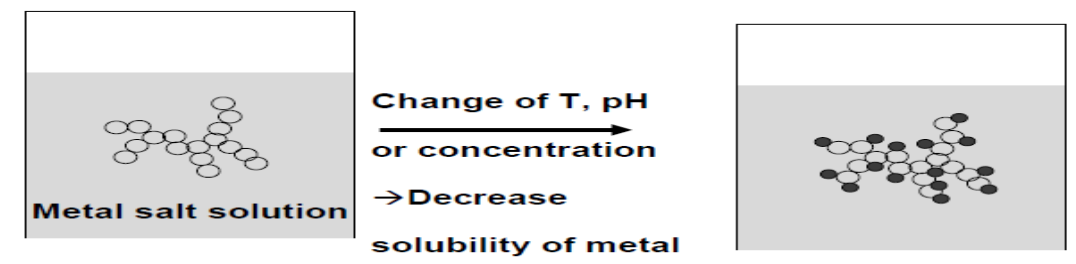

Fig. 3. Flow sheet of the preparation of precipitated catalysts.

Preparation of catalysts by impregnation method

This method starts with a support in the desired specification, size and shape; the precursor of the catalyst is then coated or impregnated onto the surface of the support by an incipient wetting with a minimum amount of saturated solution of the precursors mixture. Once the catalyst is impregnated on the support, it is then dried, calcinated or reduced as described above. This method is faster, and allows the final property and configuration to be controllable in advance. It is, however, harder to prepare high concentration catalyst and to obtain even dispersion of catalyst components on the surface. Special techniques are developed to deposit the catalyst on the surface skin of the pore structure (eggshell) or in the inner pore structure (eggyolk) by a competitive chemisorption of special adsorbate, e.g., citric acid, formic acid or hydrochloric acid. The eggshell arrangement of catalyst components is desirable in a diffusion-controlled reaction. The eggyolk arrangement allows the smaller reactant molecules to contact with the active component of the catalyst; this is sometimes used in the case where the reactant stream contains impurity of high molecular weight substance. Both arrangements enable the saving of precious metal ${ }^{(20,21)}$. The flow sheet of the preparation of impregnation catalysts can be presented in Fig. 4.

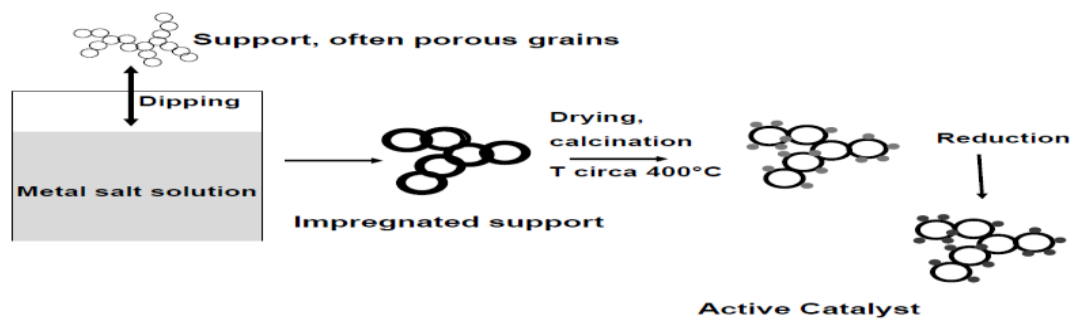

Fig. 4. The flow sheet of the preparation of impregnation catalysts.

Preparation of catalysts by deposition method

This method uses a preformed support like that in impregnation; the active components and additional salt of support (e.g. aluminum nitrate) after dissolving in water are slowly and homogeneously precipitated by hydroxide ion

Egypt. J. Chem. 55, No. 5 (2012) 
generated from a hot urea solution. By this way, the hydroxide of the active components and support are co-precipitated together onto the support; after drying and calcination the active components are surrounded by a thin layer of freshly formed support depositing on the original support surface. In general, this method yields a catalyst with smaller particle sizes in better dispersion and larger surface area and allows incorporation of higher loading of the active components.

\section{Sol-gel technique for catalysts preparation}

The sol-gel technology was used in order to synthesize materials with good homogeneity and high purity; using this method the materials can be processed at low temperatures and during short periods; it is possible to control the size and, in most of the cases, also the shape of the particles. Urea is used as gelifying agent due to its low decomposition temperature $\left(200-250^{\circ} \mathrm{C}\right)$ compared with other gelifying agents (citric acid, polyvinyl alcohol..., etc. ${ }^{(19)}$.

Previous studies have caused big interest in using the sol-gel process for the preparation of oxide compounds. The inorganic sol-gel process is one wellknown synthetic route for the preparation of various oxide materials $\left(\mathrm{SiO}_{2}, \mathrm{~V}_{2} \mathrm{O}_{5}\right.$, and $\mathrm{SnO}_{2}$ ). The sol-gel synthesis is based on the hydrolysis of inorganic precursors in aqueous solution followed by the condensation, gelation, aging, drying and densification (Fig. 5). In this process, liquid precursor materials are reacted to form a sol, which then polymerizes into an inorganic polymeric gel and hence the gel was dried to produce aerogel and xerogel.

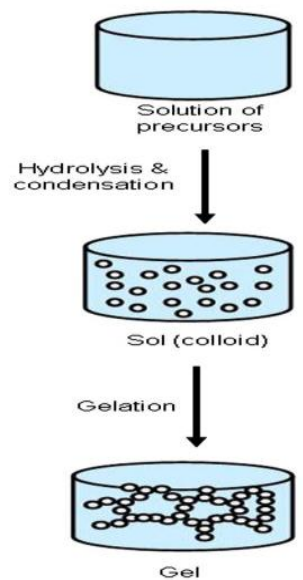

Fig. 5. Schematic of the routes that one could follow the scope of sol-gel process.

Preparation of catalysts by spray pyrolysis

Spray pyrolysis is a process in which a solid is obtained by spraying a solution into a series of reactors where the aerosol droplets undergo evaporation of the solvent and solute condensation within the droplet, followed by drying and thermolysis of the precipitated particle at higher temperature ${ }^{(22)}$. This procedure 
gives rise to microporous solids, which finally sinter to form dense particles. This method represents a convenient procedure for obtaining finely dispersed particles of predictable shape, size, and variable composition. The resulting powders generally consist of spherical particles, the final diameter of which can be predetermined from that of the original droplets. The method offers certain advantages beside other more commonly used techniques (such as precipitation from homogenous solution) as it is simple, rapid, and continuous. Recently, for example, it is used for the production of materials with relevant properties, say mesoporous microspheres ${ }^{(23)}$ and phosphorescent nanoparticles ${ }^{(24)}$.

\section{Preparation of catalysts by high energy ball milling}

Processing of materials by high-energy ball milling (HEBM) is an attractive new method in preparing novel materials ${ }^{(25)}$, which decreases the crystallite and particle size and induces the continuous formation of the structural defects through the cycling cut and deformation of large crystallites. Therefore, highenergy ball milling techniques are well suited for manufacturing large quantity of nanomaterials (Fig. 6) ${ }^{(26)}$.

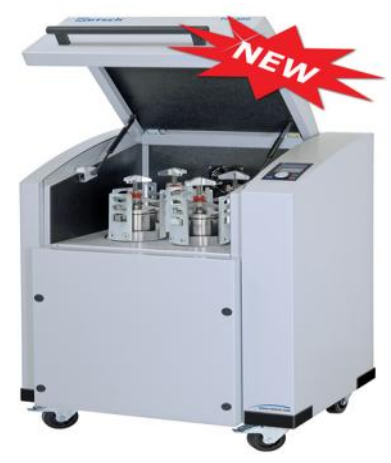

Fig. 6. High energy ball milling.

\section{Photocatalysts preparation}

Photolytic chemical process such as splitting of water ${ }^{(27,28)}$, reduction of carbon dioxide for the conversion of solar energy into chemical energy ${ }^{(29)}$ and wet-type solar cells ${ }^{(30)}$. In addition to applying photocatalysts for energy renewal and energy storage, applications of photocatalysts to environmental cleanup have been one of the most active areas in heterogeneous photocatalysis ${ }^{(31)}$. This is inspired by the potential application of $\mathrm{TiO}_{2}$ based catalysts for the complete destruction of organic contaminants in polluted air and waste water ${ }^{(32)}$.

In chemistry, photocatalysis is the acceleration of a photoreaction in the presence of a catalyst. In photogenerated catalysis, the photocatalytic activity (PCA) depends on the ability of the catalyst to create electron-hole pairs, which generate free radicals (hydroxyl radicals: $\mathrm{OH}$ ) able to undergo secondary reactions ${ }^{(33)}$. Its comprehension has been made possible ever since the discovery

Egypt. J. Chem. 55, No. 5 (2012) 
of water electrolysis by means of the titanium dioxide. Commercial application of the process is called Advanced Oxidation Process (AOP). There are several methods of achieving AOP's, that can but do not necessarily involve $\mathrm{TiO}_{2}$ or even the use of UV light. Generally the defining factor is the production and use of the hydroxyl.

\section{Preparation of catalysts by microemulsions}

Microemulsion media is formed on addition of an aliphatic alcohol (cosurfactant) to an ordinary emulsion. However, a three-component system consisting of oil, water and surfactant may produce microemulsions as well. Three factors characterize a microemulsion: transparency (optical isotropy), droplet size (6 to $80 \mathrm{~nm}$ ) and stability (thermodynamic). There are three types of microemulsions: water-in-oil, oil-in-water and bicontinuous microemulsions ${ }^{(34)}$.

The synthesis of inorganic nanoparticles is usually carried out in water-in-oil microemulsions which consist of small aggregates (micelles) at the microscopic level. The water core of these aggregates is surrounded by the surfactant molecules which have the polar part of their molecules towards the oil phase. In the water core of these aggregates, electrolytes may be solubilised, for instance metal salts. These metal salts will then be transformed into inorganic precipitates by using an appropriate reducing or precipitating agent. These agents can be directly added to the microemulsion containing the metal precursors, or first solubilised in a microemulsion similar to the one containing the metal precursor, as illustrated in Fig. 7.

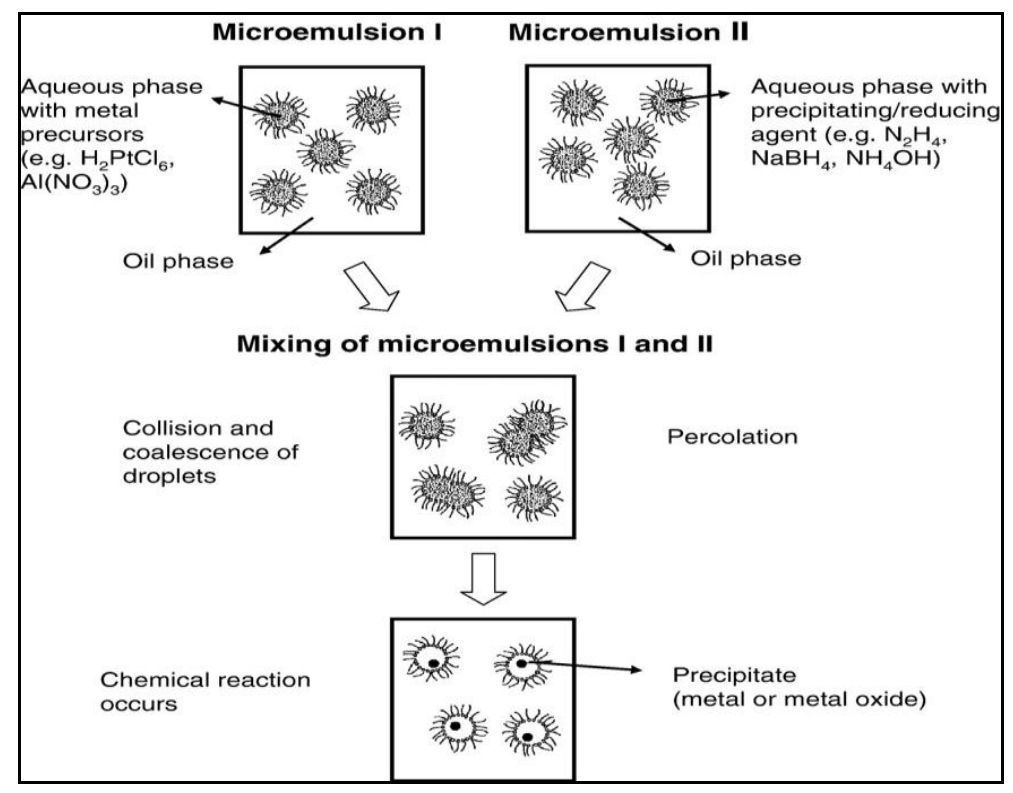

Fig. 7. Formation of metal particles from reverse (w/o) microemulsions ${ }^{(35)}$.

Egypt. J. Chem. 55, No. 5 (2012) 
The latter way of preparation is more favorable for achieving a homogeneous distribution of the precipitating/reducing agent which will rapidly react with the metal precursors through the collision and coalescence between two aggregates containing the different reactants. The reaction (nucleation) will take place essentially at the same time in the whole microemulsion media which will favor the formation of a large number of nuclei inside the water cores of the micelles. These nuclei will very rapidly grow through material exchange between micelles (particle growth) to give the final particle size. At this stage, inorganic particles stabilized by the surfactant molecules, and water-containing micelles, are suspended in the oil phase. Two other important parameters that affect the final particle size are the $W_{0}$ (Water-to-surfactant molar ratio) and the metal salt concentration in the water phase. These parameters contribute to the determination of the number of nuclei formed (relatively slow process) upon addition of reducing/precipitating agents before the particle growth (fast process) starts $^{(36)}$.

\section{Nanotechnology and the environment}

Nanotechnologies identify ways to support environmentally beneficial approaches such as green energy, green design, green chemistry, and green manufacturing. Responsible manufacturing which incorporates principles of green chemistry and environmentally responsible production of nanomaterials such as making use of reusable and recyclable materials, restricting the use of environmentally friendly materials such as reducing agents, capping agents and dispersants... etc. that are multifunctional. Examples of green manufacturing range from processes employing environmentally friendly chemicals with minimum energy requirements to producing silver and gold nanoparticles, among other noble nanometals, using benign reagents such as vitamin B2, ${ }^{(37)}$, vitamin $\mathrm{C}^{(38)}$ and tea and coffee extract ${ }^{(39)}$.

\section{Applications}

Alkylation

The alkylation of aromatic compounds is widely used in the large-scale synthesis of petrochemicals, fine chemicals, and intermediates ${ }^{(40)}$. This reaction consists of the replacement of a hydrogen atom of an aromatic compound by an alkyl group derived from an alkylating agent. If the hydrogen being replaced is on the aromatic ring, the reaction is electrophilic substitution, which requires an acid catalyst. If the hydrogen being replaced is on the side chain of an aromatic molecule, then base catalysts or radical conditions are needed.

Acid catalysts used for alkylation of aromatic hydrocarbons are Brønsted acids containing acidic protons. These typically have included acidic halides such as $\mathrm{AlCl}_{3}$ and $\mathrm{BF}_{3}$; protonic acids, especially sulfuric acid, hydrofluoric acid, and phosphoric acid; acidic oxides and zeolites; and organic cation exchange resins. The acidic halides and protonic acids are being rapidly replaced for largescale applications by solid alkylation catalysts, especially zeolites, because these are much more desirable for environmental reasons. They are noncorrosive and

Egypt. J. Chem. 55, No. 5 (2012) 
offer additional advantages for controlling the selectivity via their shapeselective properties. This brief overview focuses on recent developments related to the synthesis and applications of novel solid catalysts in the alkylation of aromatic compounds in which the nanoscale pore environment of a solid catalyst is exploited to achieve superior activity and shape selectivity.

\section{Dehydrogenation and hydrogenation}

There is a number of recent developments related to synthesis and application of novel metal nanoparticle and other nanostructured catalysts in two broad classes of heterogeneously catalyzed organic reactions, dehydrogenation and hydrogenation. A wide spectrum of both dehydrogenation and hydrogenation reactions is catalyzed by noble metal catalysts (e.g., palladium [Pd] and platinum [Pt]) dispersed on metal oxide supports, whereas dehydrogenation reactions, including oxidative dehydrogenation reactions (ODH), are also catalyzed by supported transition metal oxides, such as vanadium pentoxide $\left(\mathrm{V}_{2} \mathrm{O}_{5}\right)$, molybdenum trioxide $\left(\mathrm{MoO}_{3}\right)$, and chromic acid $\left(\mathrm{Cr}_{2} \mathrm{O}_{3}\right)$.

\section{Dehydrogenation}

Recently, McCrea and Somorjai ${ }^{(41)}$ demonstrated that the rate of cyclohexene hydrogenation and dehydrogenation is influenced by the symmetry of the platinum single crystal faces. They concluded that the maximum turnover rate of hydrogenation appeared at lower temperature than the dehydrogenation, and the maximum hydrogenation rate was higher on Pt (lllll) while lower on Pt $\left(\begin{array}{lll}1 & 0 & 0\end{array}\right)$ faces compared to the rate of dehydrogenation. The phenomenon was traced back to the difference of reaction mechanisms on the two different surfaces and serves as an excellent test reaction occurring with different rates over different crystal faces. Such nanostructured catalytic materials confined to cavities and pores of regular nanoscale dimensions are the subject of continuing interest because they have unique size-dependent catalytic properties, which are significantly different than those of the corresponding bulk catalysts ${ }^{(42)}$. The fabrication of metallic Pt nanoparticles with controllable size and shape has become an important topic in nanotechnology owing to their unique catalytic performance.

\section{Hydrogenation}

The use of well-defined metal nanoparticles $(1-10 \mathrm{~nm})$ for catalytic processes is a rapidly growing area ${ }^{(43-46)}$. Similarly to molecular complexes, metal nanoparticles have been proved to be efficient and selective catalysts not only for hydrogenation of olefins or $\mathrm{C}-\mathrm{C}$ couplings, but also for reactions that are not catalyzed or are poorly catalyzed by molecular species, such as hydrogenation of arenes. However, despite impressive progress in asymmetric "catalysis, few colloidal systems have been found to display an interesting activity in this field. Those systems that show promise include $\mathrm{Pt}(\mathrm{Pd}) /$ cinchonidine for the hydrogenation of ethyl pyruvate and Pd-catalyzed kinetic resolution of racemic substrates in allylic alkylation. 


\section{Selective oxidation}

Selective oxidation processes represent a large class of organic reactions where the development of clean and efficient "green chemistry" processes can have a significant positive economic and environmental impact to mitigate the accumulation of greenhouse gases in the atmosphere and other environmental concerns resulting from the world's growing consumption of fossil fuels and current fuel processing techniques. Selective oxidation processes leading to chemical intermediates and fine chemicals have up to now largely relied on stoichiometric reactions employing chromate, permanganate, and renate species. Simple catalytic reactions making use of molecular oxygen or hydrogen peroxide that require minimal energy and produce minimal by-product waste are highly desirable in order to replace stoichiometric reactions that are expensive and environmentally unfriendly ${ }^{(47)}$.

Recent development of a new generation of hydrotreating

Catalysts presents an example of commercial success in this direction. Hydrotreating catalysts comprising $\mathrm{Co}, \mathrm{Ni}$, and Mo supported on $\gamma$-alumina have been widely used in refinery for upgrading heavy crude oils and for production of ultra-low sulfur diesel and gasoline fuels. The hydrotreating process has been in commercial use for many decades. As shown in Fig. 8, incremental improvement was made by optimization of catalyst bed structures, catalyst particle shape, pore size and pore size distribution, and catalyst loading, typical macro- and micro- scale modification. A step change is realized by nano-scale catalyst engineering. Instead of using a support, a composite of metal oxides is prepared of desired composition and size that is particularly active for hydrotreating reactions ${ }^{(48)}$. The resulting catalyst powder is formed into catalyst particle shapes suitable for packed bed loading, which gives much higher density of active catalyst "sites" than the supported ones ${ }^{(49,50)}$.

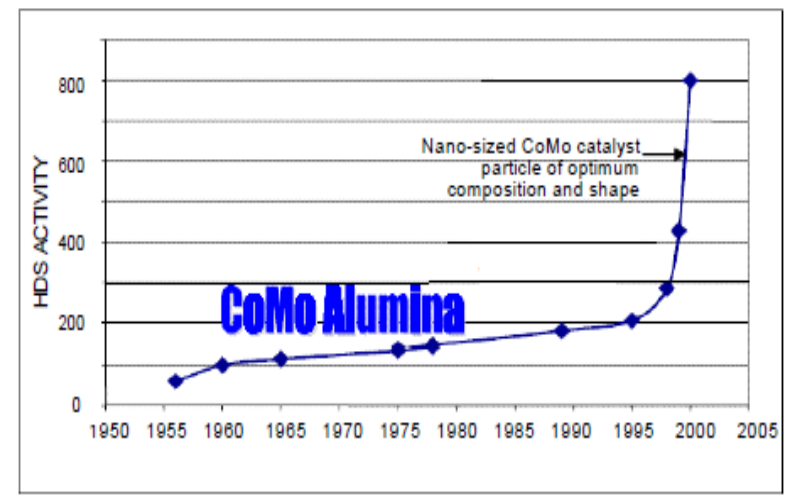

Fig. 8. Development of HDS catalyst in the past 50 years ${ }^{(50)}$. 
The Argonne ${ }^{(51)}$ technology can be used to produce transparent nanoclay dispersions in many thermoplastic polymers at clay loadings of 2-20 percent or higher (as picture). The oxygen barrier properties of these nanocomposite films are more than 200,000 times better than oriented polypropylene and over 2,000 times better than Nylon-6. The technology reduces by tenfold the requirement for costly organic modifiers (Fig. 9).

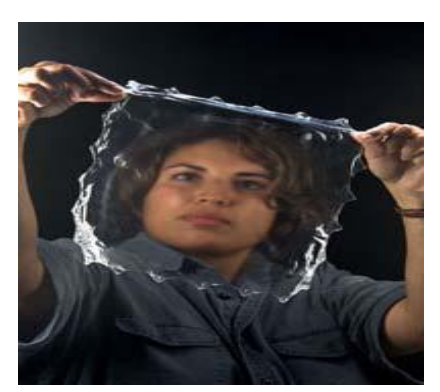

Fig. 9. The Argonne technology

Nanotechnologies for renewable energy applications

As the world faces serious energy challenges, the development and implementation of renewable energy technologies became increasingly important Fig. 10). Mao and $\mathrm{Chen}^{(52)}$ offer a glimpse of the role nanotechnology, in particular, innovations of nanostructures and nanomaterials, is playing in the development of selected renewable energy technologies. These technologies, based on the authors' research interests, include (1) converting the energy of sunlight directly into electricity using solar cells; (2) converting solar energy into hydrogen fuel by splitting water into its constituents; (3) storing hydrogen in solid-state forms; and (4) utilizing hydrogen to generate electricity through the use of fuel cells. It is clear that nanotechnology enabled renewable energy technologies starting to scale up dramatically. Later on, as they become mature and cost effective in the decades to come, renewable energy could eventually replace the traditional, environmentally unfriendly, fossil fuels.

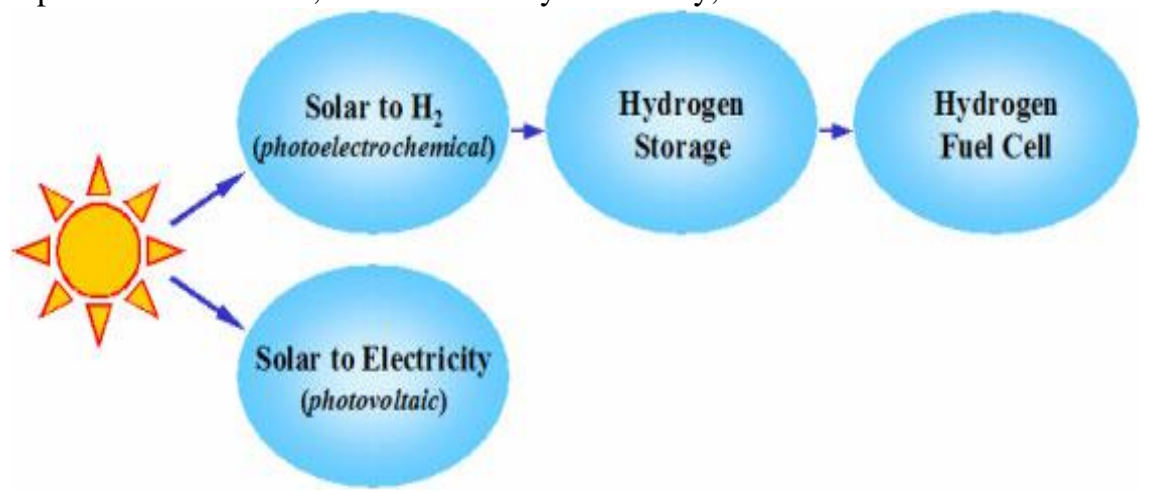

Fig. 10. Renewable energy technologies.

Egypt. J. Chem. 55, No. 5 (2012) 
Catalytic converters

Catalytic converters (Fig. 11) change poisonous molecules like carbon monoxide and various nitrogen oxides in car exhausts into more harmless molecules like carbon dioxide and nitrogen. They use expensive metals like platinum, palladium and rhodium as the heterogeneous nanocatalyst. The metals are deposited as thin layers onto a ceramic honeycomb. This maximises the surface area and keeps the amount of metal used to a minimum.

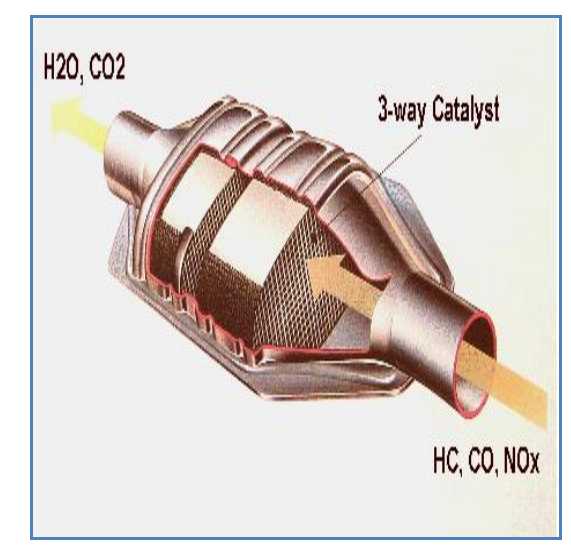

Fig. 11. Ceramic honeycomb and catalytic converters.

\section{Future of nanocatalysis}

Unprecedented opportunities are arising for re-engineering existing products. For example, cluster of atoms (nanodots, macromolecules), nanocrystalline structured materials (grain size less than $100 \mathrm{~nm}$ ), fibres less than $100 \mathrm{~nm}$ in diameter (nanorods and nanotubes), films less than $100 \mathrm{~nm}$ in thickness provide a good base to develop further new nanocomponents and materials.

The buckyball (C60) has opened up an excellent field of chemistry and material science with many exciting applications because of its ability to accept electrons. Carbon nanotubes have shown a promising potential in the safe, effective and risk free storage of hydrogen gas in fuel cells, increasing the prospects of wide uses of fuel cells and replacement of internal combustion engine. The potential of nanotubes can be further exploited in oil and gas industry. The nanotube market is likely to hit 1.35 billion dollars in 2005 . Nanotechnology offers a myriad of applications for production of new gas sensors, optical sensors, chemical sensors, and other energy conversion devices to bio implants.

\section{Solar cells}

Nanoporous oxide films such as $\mathrm{TiO}_{2}$ are being used to enhance photo voltaic cell technology. Nanoparticles are perfect to absorb solar energy and they can be used in very thin layers on conventional metals to absorb incident solar energy.

Egypt. J. Chem. 55, No. 5 (2012) 
New solar cells are based on nanoparticles of semi conductors, nanofilms and nanotubes by embedding in a charge transfer medium. Films formed by sintering of nanometric particles of $\mathrm{TiO}_{2}$ (diameter 10-20 nm) combine high surface area, transparency, excellent stability and good electrical conductivity and are ideal for photovoltaic applications. Non porous oxide films are highly promising material for photovoltaic applications. Nanotechnology opens the opportunity to produce cheaper and friendlier solar cells.

\section{Nanofibres}

In China and U.K., nanocarbon fibres have been produced. The production of nanofibres offers the potential of using the woven reinforcement as body armor.The future soldier's uniform would incorporate soft woven ultra strong fabric with capabilities to become rigid when a soldier breaks his legs and would protect him against pollution, poisoning and enemy hazards.

\section{Sensors}

Nanotechnology offers unlimited opportunities to produce new generation pressure, chemical, magneto resistive and anti-collision automobile sensors. Many of the novel applications such as new sensors, better photovoltaic cells, lighter and strong materials for defense, aerospace and automotives are already in use, and applications such as anti-corrosion coating, tougher and harder cutting tools, and medical implants and chips with $1 \mathrm{~nm}$ features may be developed in another 5-15 years. Nanostructured materials for nanoelectronic components, ultra fast processors, nanorobots for body parts are still in the state of infancy.

\section{Ultra light materials}

Nanotechnology is viewed as a key technology for the development of ultra light materials which would result in energy, fuel and materials savings and development of spectacular materials with complete control over structure and properties at a subatomic level not hitherto known to scientists and engineers. With the future development of nanocatalyst, diesel oxidant using nanoscale layers of $\mathrm{Pt}, \mathrm{Pd}$, the major environmental killers smog, pollution and toxic pesticide would be eliminated and humans will be able to breathe in healthy air. Improvement in nanofilters would enable bacteria less than $30 \mathrm{~nm}$ to be filtered and achieve water purity of 99.999997. The future avalanche of nano-age involves replacement of existing chips by super chips, plastic semiconductors, stronger and lighter jet fighters, amazingly invisible clothing for soldiers, super fuel cells and super batteries. The next twenty years would unleash a new era of nanotechnology when a fullerene molecule (C60) would be described in a high school chemistry book and all materials science textbooks would contain chapters on nanomaterials. 
Corrosion and corrosion prevention

Despite the progress in understanding the structure of nanomaterials, there is no evidence to show that nanomaterials are more resistant to corrosion than their conventional counterparts. A typical feature of nanomaterials is the defect core structure, which is caused by incorporation of vacancies, dislocations, grains or interphase boundaries, which alter the density and conduction in defect core regions where $50 \%$ of the atoms are located. All misfits are concentrated in the grain boundary. The grain boundary is associated with high diffusivity and higher electrical resistivity. Solute atoms with little solubility also segregate into the boundary regions. Summing up, the grain boundary region is highly active in nanomaterials. Nanograin size, enhanced diffusivity and concentration of defects would make grain boundary sensitive to attack by corrosion. Increased electrical resistivity due to electron scattering would enhance corrosion resistance. Increased number of grain boundaries would also lead to development of more anodic sites for nucleation of corrosion. Theoretically, the structural evidence does not present an optimistic picture of corrosion resistance. There is no clear evidence to prove that nanomaterials are more resistant to corrosion than conventional materials. This is in contrast to the corrosion prevention of nanostructured materials as the studies on coatings have proved. Nanoparticles incorporated in coatings have shown a dramatic resistance to corrosion of the substrate due to their hydrophilic, anti-wear, anti-friction and self-cleaning properties. Engine components are subjected to severe environmental stimulus for corrosion. Diesel engines produce sulfuric acid and formic acid as combustion products. Nano Zirconia powder has been used to coat engine components by plasma spray with success. Nanocoatings create a lotus effect and properties, which keeps corrosion away.

\section{Space Elevator}

The space elevator was first proposed in the 1960s as a method of getting into space. The initial studies of a space elevator outlined the basic concept of a cable strung between Earth and space but concluded that no material available at the time had the required properties to feasibly construct such a cable. With the discovery of carbon nanotubes (Fig. 12) in 1991 it is now possible to realistically discuss the construction of a space elevator (Fig. 13). Although currently produced only in small quantities, carbon nanotubes appear to have the strength-to-mass ratio required for this endeavor. However, fabrication of the cable required is only one of the challenges in construction of a space elevator. Powering the climbers, surviving micrometeor impacts, lightning strikes and low-Earth-orbit debris collisions are some of the problems that are now as important to consider as the production of the carbon nanotube cable. We consider various aspects of a space elevator and find each of the problems that this endeavor will encounter can be solved with current or near-future technology.

Egypt. J. Chem. 55, No. 5 (2012) 




References

1. Oxford, S.M., Henao, J.D., Yang, J.H., Kung, M.C. and Kung, M.C. Understanding the effect of halide poisoning in $\mathrm{CO}$ oxidation over Au/TiO2. Appl. Catal. A: 339 (2, 1), 180-186 (2008).

2. Kung, H. H. and Kung, M.C., Nanotechnology and Heterogeneous Catalysis Springer, New York (2007).

3. Mishra, M. K., Tyag, B. and Jasra, R.V., Synthesis and characterization of nanocrystalline sulfated zirconia by sol-gel method. J. Mol. Catal. A: Chem. 223, 61-65 (2004).

4. Jones, S. D., Neal, L. M. and Hagelin-Weaver, H. E., Steam reforming of methanol using $\mathrm{Cu}-\mathrm{ZnO}$ catalysts supported on nanoparticle alumina. Appl. Catal. B: Environ. 84 (3-4), 631-642 (2008).

5. Wegener, G., Brandt, M., Duda, L., Hofmann, J., Klesczewski, B., Koch, D., Kumpf, R. and Orzesek, H., Trends in industrial catalysis on polyurethane industry. Appl. Catal. A: General, 221 (1-2), 303-335 (2001).

6. Narayanan, R., Shape-dependent nanocatalysis and the effect of catalysis on the shape and size of colloidal metal nanoparticles. Thesis for the Degree Doctor of Philosophy in Chemistry, Georgia Institute of Technology, March (2005).

7. Nutzenadel, C., Zuttell, A., Chartouni, D., Schmid, G. and Schlapbach, L., Critical size and surface effect of the hydrogen interaction of palladium clusters. Eur. Phys. J., D 8, 245-250 (2000). 
8. Thomas, J.M. and Thomas, W.J., Principles and Practice of Heterogeneous Catalysis. ( $2^{\text {nd }}$ ed.), Wiley-VCH, Weinheim (1997).

9. Gates, B.C., Catalytic Chemistry, Wiley, New York (1992).

10. Morbidelli, M., Gravriilidis, A. and Varma, A., Catalyst Design: Optimal Distribution of Catalyst in Pellets, Reactors and Membranes. Cambridge University Press, Cambridge, UK (2001).

11. Bartholomew, C.H. and Farrauto, R.J., Fundamentals of Industrial Catalytic Processes. ( $2^{\text {nd }}$ ed.), Wiley-AIChE (2005).

12. Bowker, M., The Basis and Applications of Heterogeneous Catalysis. Oxford Science Publications (1998).

13. Anastas, P.T. and Warner, J.C., Green Chemistry: Theory and Practice. Oxford University Press, Oxford, UK (1998).

14. van Santen, R.A. and Neurock, M., Molecular Heterogeneous Catalysis. A Conceptual and Computational Approach. Wiley-VCH, Weinheim (2006).

15. Bell , A.T., Science, 299, 1688-1691 (2003).

16. Lee, I., Delbecq, F., Morales, R., Albiter, M.A. and Zaera, F. , Tuning selectivity in catalysis by controlling particle shape. Nat. Mater. 8, 132-138(2009).

17. Mohamed, R.M., Characterization and catalytic properties of nano-sized Pt metal catalyst on $\mathrm{TiO} 2-\mathrm{SiO} 2$ synthesized by photo-assisted deposition and impregnation methods. J. Mater. Process. Technol. 2091 (1), 577-583 (2009).

18. Goldstein, A.N., Handbook of Nanophase Materials. Marcel Dekker, Inc., New York (1997).

19. Masala, O. and Seshadri, R. Synthesis routes for large volumes of nanoparticles synthesis. Annu. Rev. Mater. Res. 34, 41-81 (2004).

20. van Dillen, A.J., Terörde, R.J. A.M., Lensveld, D.J., Geus, J.W. and de Jong, K.P., Synthesis of supported catalysts by impregnation and drying using aqueous chelated metal complexes. J. Catal. 216 (1-2), 257-264 (2003).

21. Farias, R. F. D., Arnold, U., Martinez, L., Schuchardt, U., jannini, M. J. D. M. and Airoldi, C., Synthesis, characterization and catalytic properties of sol-gel derived mixed oxides. J. Phys. and Chem. Solids, 64, 2385-2389 (2003).

22. Mädler, L., Kammler, H. K., Mueller, R. and Pratsinis, S. E., Controlled synthesis of nanostructured particles by flame spray pyrolysis. J. Aerosol. Sci. 33 (2), 369-389 (2002).

23. Darabont, A., Nemes-Incze, P., Kertésza, K., Tapasztóa, L., Koósa, A. A., Osvátha, Z., Sárközi, Zs., Vértesya, Z., Horvátha, Z.E. and Biró, L.P., Synthesis 
of carbon nanotubes by spray pyrolysis and their investigation by electron microscopy. J. Optoelectronics and Adv. Mater. 7 (2), 631 - 636 (2005).

24. Eslamian, M. and Okuyama, K., Modelling of nanoparticle formation during spray pyrolysis. Nanotechnol. 17, 1674-1685(2006).

25. Stubicar, M., Blazina, Z., Tonejc, A., Stubicar, N. and Krumes, D., The effect of high energy ball milling on the crystal structure of GDNi5. Physica, B, 304-308 (2001).

26. Chen, H., Wang, J.M., Pan, T., Xiao, H.M., Zhang, J.Q. and Cao, C.N., Effects of high-energy ball milling (HEBM) on the structure and electrochemical performance of nickel hydroxide.Int. J. Hydrogen Energy, 28, 119 - 124 (2003).

27. Ni, M., Leung, M.K.H., Leung, D.Y.C. and Sumathy, K., A review and recent developments in photocatalytic water-splitting using $\mathrm{TiO} 2$ for hydrogen production. Renew. Sust. Energy Rev. 11, 401-425 (2007).

28. Zou, Z. G., Ye, J. H., Sayama, K. and Arakawa, H., Direct splitting of water under visible light irradiation with an oxide semiconductor photocatalyst. Nature, 113 (414), 625-627 (2001).

29. Koci, K., Obalova, L., Matejova, L., Placha, D., Lacny, Z., Jirkovsky and J. Solcova, O. "Effect of $\mathrm{TiO} 2$ particle size on the photocatalytic reduction of $\mathrm{CO}_{2}$, Appl. Catal. B 89, 494-502 (2009).

30. Thompson, T. L. and Yates, J. T., Surface science studies of the photoactivation of TiO2-new photochemical processes. Chem. Rev. 106, 4428-4453(2006).

31. Hoffmann, M.R., Martin, S.T., Choi, W.Y. and Bahnemann, D.W., Environmental applications of semiconductor photocatalysis. Chem. Rev. 95- 69-96 (1995).

32. Thompson, T. L. and Yates, J. T., Surface science studies of the photoactivation of TiO2-new photochemical processes. Chem. Rev. 106, 4428-4453 (2006).

33. Linsebigler, A.L., Lu, G.Q. and Yates, J.T., Photocatalysis on TiO2 surfaces principles, mechanisms, and selected results. Chem. Rev. 95, 735-758 (1995).

34. Eriksson, S., Nylén, U., Rojas, S. and Boutonnet, M., Preparation of catalysts from microemulsions and their applications in heterogeneous catalysis. Appl. Catal. A Gen, 265(2), 207-219 (2004)

35. Capek, I., Preparation of metal nanoparticles in water-in-oil (W/O) Microemulsions. Adv. Colloid Interface Sci, 110, 49-74 (2004).

36. Boutonnet, M., Lögdberg, S. and Svensson, E.E., Recent developments in the application of nanoparticles prepared from w/o microemulsions in heterogeneous catalysis. Colloid \& Interface Sci. 13, 270-286 (2008). 
37. Nadagouda, M.N. and Varma, R.S., Green and controlled synthesis of gold and platinum nanomaterials using vitamin B2: density-assisted self-assembly of nanospheres, wires and rods. Green Chem. 8, 516-518 (2006).

38. Nadagouda, M.N. and Varma, R.S., A greener synthesis of core ( $\mathrm{Fe}, \mathrm{Cu})$-shell ( $\mathrm{Au}$, $\mathrm{Pt}, \mathrm{Pd}$ and Ag) nanocrystals using aqueous vitamin C. Cryst. Growth Design, 7, 25822587 (2007).

39. Nadagouda, M.N. and Varma, R.S., Green synthesis of silver and palladium nanoparticles at room temperature using coffee and tea extract. Green Chem. 10859862 (2008).

40. In: G. Ertl, H. Knözinger and J. Weitkamp, Editors, Handbook of Heterogeneous Catalysis Vol. 5, VCH, Weinheim (1997).

41. McCrea, K.R. and Somorjai, G.A., J. Mol. Catal. A: Chem. 163, 43-53 (2000).

42. Rupprechter, G., Catal. Today, 17,1263 (2007).

43. Astruc, D., Lu, F. and Aranzaes, J.R., Angew. Chem., Int. Ed. 44, 7852-7872 (2005).

44. Chandler, B.D. and Gilbertson, J.D., Top. Organometal. Chem. 20, 97-120 (2006).

45. Tsuji, Y. and Fujihara, T., Inorg. Chem. 46, 1895-1902 (2007).

46. Andres, R., De Jesus, E. and Flores, J.C., New J. Chem. 31, 1161-1191 (2007).

47. Haruta, M., Chem. Rec. 3, 75-87 (2003).

48. Liu, W., Catalyst technology development from macro-, micro- down to nano-scale. China Particuology, 3 (6), 383-394 (2005).

49. Soled, S.L., Riley, K.L. and Schleicher, G.P., Hydroprocessing using bulk group VIII/group VIB catalysts. U.S Pat. 6162 350. Exxon Research and Engineering Company (2000).

50. Pappal, D. A., Plantenga, F. L., Tracy, W. J., Bradway, R. A., Chitnis, G. and Lewis, W. E., Stellar improvements in hydroprocessing catalyst activity. NPRA Annual Meeting, AM-03-59, Mar. 23-25, San Antonio, TX, (2003).

51. Argonne's Chemical Engineering Division:http://www.cmt.anl.gov/, April (2003).

52. Mao, Y. and Chen, X., Selected nanotechnologies for renewable energy applications.Int. J. Energy Res. 31, 619- 636 (2007).

(Received 18/7/2012; accepted 26/8/2012 ) 


\section{الحفز والتكنولوجيا النانوية}

سهام على شعبان م البترول - مدينة نصر - القاهرة - مصر.

يمكن فهم تكنولوجيا النانو والتكنولوجيا من تصميم وتصنيع وتطبيقات النانو

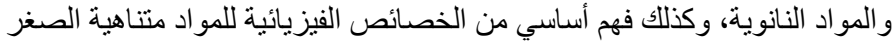

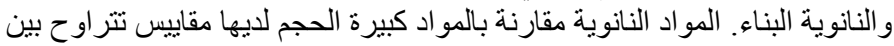

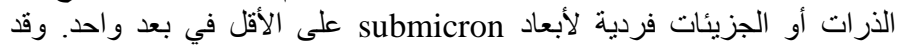

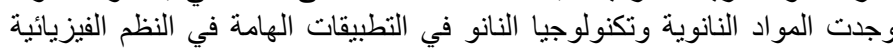

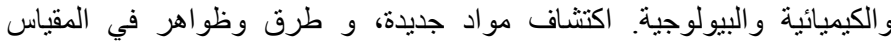

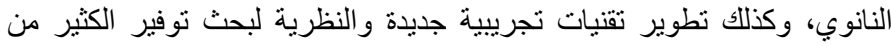

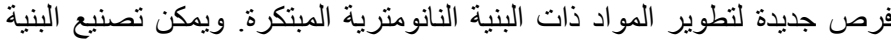

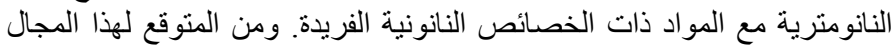
ان يفتح مجالات جديدة في مجال العلوم والت التكنولو النيا. 